\title{
The Ice Cracks for Frozen Flow: Comprehending the Irony of Development through Metaphor of Water
}

\author{
Bhumika Sharma* $^{*}$
}

\begin{abstract}
Water, one of the five elements, runs through the course of evolution as life line. Conceived as the source of origin, sustenance and annihilation, it is believed to be the crux of existence. Whether scientific or mythical, it serves as the foundation of cyclical nature of life that begins with Ice Age and ends in great Deluge. Water, being chiefly conceived as the life giving fluid, is mainly associated with the flow that designates existence. But interestingly, the flow of water does not remain restricted to single form or shape. Through its adaptability, malleability and transforming flamboyance, it narrates the beauty, splendour, exoticism, functionality, and dynamism inherent in nature. In literary and cultural discourses water emerges as a chief motif to communicate concrete as well as abstract realities of life. Envisaged in myriad forms such as haze, mist, fog, frost, ice, vapour, and so on it appears in various semblances and disguise to whisper some message in human ears. Its dripping sound echoes the essence of being. Creating a wondrous spectrum of variability, it extends from tiny dew drops to vast oceans. In fact, the metaphor of water serves one of the foundational artistic imagery of visualising life. Present paper studies how water is projected in our literary and cultural discourses to comprehend various experiential truths of human civilisation. It probes into the mystery of incredulous development of humankind that amazes with its incredible achievements. Human civilisation may boast of its consistent progress over the years, but literary delineations in the metaphorical renderings of water question how far do we agree with the progressive march of humankind. What are the ironies that constitute the dilemma of human rationality and the development of a civilisation across cultures?

Keywords: Cyclical Nature of Life, Literary and Cultural Discourses, Motif, Human Civilisation, Irony, Human Rationality
\end{abstract}

\footnotetext{
Corresponding author: Bhumika Sharma; Assistant Professor, Central University of Rajasthan, Bandar Sindri, Ajmer Rajasthan, India; e-mail: sharmabhumika@curaj.ac.in
} 
All living beings are formed out of the energies and synergies of the natural power of five elements. Named as Earth, Water, Fire, Air and Space, these forces are said to be responsible for shaping the mould of various organism. Each of the elements gifts us with a specific property. Earth incorporates firmness whereas Space denotes infinity. This is complemented by the lightness represented in the Air, blaze imported by Fire and flow indicated by Water. Since these elements are the core of creation composing wonderful symbiosis in nature each of these is a precious resource to be honoured by human beings. These all preserve and promote what is considered to be the quintessential of human civilisation. Their symbolic significations turn them into eternal code of human thoughts and actions. Their figurative constellation scripts the history of human evolution. One may interestingly navigate various literary and cultural practices to witness how artistic endeavours by man have woven these elemental forces of nature into threads of anthropological and philosophical history of man. As the metaphor of water serves one of the foundational artistic imagery of visualising life, it contours the deep contemplation over the human existence. How does it shape human imagination to understand the present status of human civilisation? We may strive to answer many of such questions in our attempt to understand human history of development.

Let's probe into the mystery of incredulous development of humankind that amazes with its incredible achievements. The issues that may boggle our mind will be numerous. Does the progression of mankind evince man's victory over nature or simply implies the idea of reckless exploitation of natural resources? How is it reflected in our literary and cultural discourses? What imagery do we use to answer certain dubious questions that evade straight answers? Do our discourses impart knowledge to ruminate before leaping into dangers of unknown lands? Or these are merely verbal wizardry to play with? Is it possible to materialise the desired growth without exploitative approach? Or have we really been greedy in our dreaming? Which thin line distinguishes a genuine aspiration from a fatal ambition or creepy annihilation? Are we on the verge of collapse? Or we would like to mock at such stupid apprehensions of weaker hearts? In view of such vital question, perhaps, it is compulsive to sincerely feel our own pulse. Does human civilisation is actually conscious of its hazardous status of biological as well as technological superiority or we would just love to revel in our contemporary accomplishments? Perhaps, despite phenomenal exhibition 
of human superiority, there lies a vast philosophical domain for self assessment on the part of this superior species called human race. And, perhaps, we may begin our expedition with a perusal of how the literary metaphor of water defines this tremendous experience of human progress.

Human civilisation may boast of its consistent progress over the years. Water, one of these five elements, runs through this course of evolution as a life line. Its emblematic connotations correspond to the equivocal nature of human existence; creation juxtaposed with cataclysm. Conceived as the source of origin, sustenance and annihilation, water is believed to be the crux of existence. Whether scientific or mythical, it serves as the foundation of cyclical nature of life that begins with Ice Age and ends in great Deluge. Given that water is chiefly conceived as the life giving fluid, it is mainly associated with the flow that designates existence. But interestingly, the flow of water does not remain restricted to single form or shape. Through its adaptability, malleability and transforming flamboyance, it narrates the beauty, splendour, exoticism, functionality, and dynamism inherent in nature.

In literary and cultural discourses water emerges as a chief motif to communicate concrete as well as abstract realities of life. Envisaged in myriad forms such as haze, mist, fog, frost, ice, vapour, and so on it appears in various semblances and disguise to whisper some message in human ears. Its dripping sound echoes the essence of being. Creating a wondrous spectrum of variability, it extends from tiny dew drops to vast oceans. Its gestures diverge from the stillness of pond to meandering river and from calmly rippling surface to tumult of roaring sea. Its presence can be felt from the wetness in soil to uninhibited trajectory of a freely floating cloud.

While beholding the transparent shimmering surface of a water body, human heart may be brimmed with curiosity to grasp its deeper secrets. How incredible it appears to imagine that deep secrets can be huddled behind the lucidity of a watery film. It appears as though Nature intends to convey secret messages through such paradoxical projections. The exterior shines with brilliance but somewhere in interior there may be the strange and unfamiliar, concealed in the darkness of its depth. With such cultural denotations, water claims to have its own majesty, mystery as well as metamorphic reality to be discovered and known by human 
imagination. Carrying numerous facets; shaped and unshaped, tangible and intangible, water imagery in literary and cultural discourses evoke subtle metaphors to comprehend the underlying truths of human experience. These are the revelations that connect concrete realities of life to abstract philosophies of human civilisation.

Life flows like water, so with the progressive move of humankind over the years. With a firm belief in the rationality of man we began our journey thousands of years back. Our literary and cultural discourses depict our experience as starting from scratch to build a palatial facade of human civilisation. Perhaps, the man rejoices boasting of such impressive inception of humankind. In his emotional and intellectual discourses he celebrates his rendezvous with destiny that began with the precious drop of water. Life must have germinated at the bottom of some water reservoir on the earth and then lifted its face to find out an out let to come forth on the surface. The conception of Ice age connotes it sprouting out from a chink in the solidified ice. Perhaps, in the chain of creation man stood somewhere amidst freezing cold waiting the warmth of life to let lose the flow from ice. The ice finally cracked and the flow of life thawed out bringing wonderful symphony of divine attributes like beauty, symmetry, equanimity and poise along with. Our various cultural discourses illustrate how wonderful it has been to script that experience in the textuality of literature.

American writer Henry David Thoreau's master piece Walden (1854) is a beautiful example of such narration. Thoreau paints a beautiful picture of the natural world and portrays the blooming life at the Walden pond. Considered as supreme work in transcendentalist writing, Walden records how human life fosters around a water reservoir. Transcending the specific identity, the narrator gradually assumes the persona of collective humankind. He probes into the relation of the order and beauty of nature to the human mind and spirit. It brings out certain sublime experiences which may be viewed in different light. Does water merely represent the substance which, as per the discipline of science, $99 \%$ of human body is made of or its power is more subtle than sensually perceived? The exotic charm of Walden pond suggests an elevating experience. Water not only formulates life but it gives additional meaning to life that has separated human beings from other inferior species. Designating the grandeur of Walden pond as a great gift of nature, not merely physical but spiritual, the author announces: 
I went to the woods because I wished to live deliberately, to front only the essential facts of life, and see if I could not learn what it had to teach, and not, when I came to die, discover that I had not lived. I did not wish to live what was not life... I wanted to live deep and suck out all the marrow of life, to live so sturdily and Spartanlike as to put to rout all that was not life. (Pg. 235)

The depth of the pond Walden turns into the deep subtle knowledge of life. Plumbing its depth becomes the human quest for knowledge. Its deep sounding watery province resonate the throbbing pulse of animate body. A physical experience turns into a metaphysical experience. In fact, there is always a close affinity between physical and metaphysical. Physical manifestation paves the way for revivifying metaphysical experiences. Similarly, what is conceived at spiritual level germinates from the material reality of life. We just need to understand how as well as how far these reflect each other. When a scientist examines the role of water in the evolution of species and explains the chemical composition of $\mathrm{H} 2 \mathrm{O}$, a literary artist in his aesthetic pursuit draws attention to the signified nature of water metaphorically keyed as the nectar of life. Their approach may be different, but both, indeed, concede in acknowledging the importance of water for survival. And in their pursuit of knowledge, its meaning evolves from physicality to metal, emotional, intellectual and spiritual realisation of life.

One may easily perceive how human mind has scaled the importance of water both in physical and metaphysical terms. Undoubtedly, man has always needed water to live physically. His every day begins with it as it was at the inception, the point of origin which goes back into Ice Age. It was the dawn of civilisation when primordial man stepped on the hard icy surface in his journey to harmonize with nature. He was engaged in collecting basic goods needed to survive. One may find such description in any scientific account of human history of civilisation. But does the image of water remain confined merely to physical necessity of human body or it extended far more in meaning and subtle signification. Water is regarded as an emblem of unfathomable mysticism. It is turned into symbol of purification. It also takes man into many more metaphysical revelations. Let's see, what Thoreau's description of morning chores reveals us: 
Then to my morning work. First I take an ax and pail and go in search of water, if that be not a dream. After a cold and snowy night it needed a diving rod to find it. Every winter the liquid and trembling surface of the pond, which was so sensitive to every breath, and reflected every light and shadow, becomes solid... Like the marmots in the surrounding hills, it closes its eyelids and becomes dormant for three months and more. Standing on the snow-covered plain, as if in a pasture amid the hills, I cut my way first through a foot of snow, and then a foot of ice, and open a window under my feet, where, kneeling to drink, I look down into the quite parlor of the fishes, pervaded by a softened light as through a window of ground glass, with its bright sanded floor the same as in summer; there a perennial waveless serenity reigns as in the amber twilight sky, corresponding to the cool and even temperament of the inhabitants. (Pg. 240)

It is not just bare animal instinct of looking resources for survival. The first person narrator of the above quoted extract is more conscious of multiple significations configured in the imagery of water. The frozen winter Walden pond represent the incarcerated existence. The mild opening denotes the crack in the hard surface assuring an inception, or more accurately, resurrection following the cyclic course of life. Exhibited in the form of moving creatures the author glimpses the beauty and velocity of life. It symbolises the dawn of civilisation awaiting a crevice to flow out from beneath the cold solid icy layer. It is the same sentiment suddenly experienced by the ancient mariner who initially forgot to praise the life emanated from the same divine source. He was guilty of disregarding the life, killing the albatross, an animate being created by same natural forces that gave birth to him. His sin is reflected in the transparency of water agonising his heart. The water turned crimson red:

But where the ship's huge shadow lay,

The charmed water burnt always

A still and awful red. (Lines 269-271) 
But, the moment he realised his mistake and paid regard to the apparent beauty and divinity of life he is forgiven, saved, and restored. His heart felt the wetness of love gushing out in the form of a spring:

Within the shadow of the ship,

I watched the water snakes:

... Within the shadow of the ship

I watched their rich attire:

Blue, glossy green, and velvet black

They coiled and swam; and every track

Was a flash of golden fire.

O happy living things! No tongue

Their beauty might declare:

A spring of love gushed from my heart,

And I blessed them unaware: (lines 272- 285)

Perhaps with every diurnal and seasonal cyclical change we experience the perpetual pattern of life that is incarnated by the elemental forces of nature. Life peeps from the hole showing the splendour of nature's creation. The winter changes into spring and it oozes out in the beautiful melted liquid form of water to prompt vegetation. We grow. We praise our swift assuring gait. We keep moving at same pace carefree, jubilant, and oblivious of side effects. We boast of our amazing scientific accomplishments. We celebrate our present status of superior race. We dream of landing in a fairy tale world full of more astonishing surprises. We rejoice of so many things that perhaps we have forgotten the count even. Is it a move towards perfection, attainment of supreme power of a creator? Then why do we feel like lamenting and doubt ourselves for making choices. Why do we feel driven by the nostalgia and crib against losing something blissful; the purity, the richness, the abundance ... and what not? The loss of the beauty of Walden pond is to be mourned. The ancient mariner reappears in the modern man without learning any lesson from the remorse of the earlier one.

Although the human race is proud of its tremendous development ever since the ice first cracked to glimpse the opulence promised by the first human endeavour, yet there appears something lacking that does not make us trust our own selections. We question ourselves of our own rationality and its idea of progression. We enquire; in our visualisation of future, have we sustained that grandeur envisaged by Thoreau in the 
magnificence of Walden pond or do we care of what imparted by Coleridge in the majestic beauty of the water snakes? Where have we dropped it down? Human endeavours asserted progression but why today, that proclamation appears dubious to us. Why do we sniff ironies in it? Have we left behind the real essence of life in the race of becoming superior species? In our attempts of fulfilling physical needs have we forgotten the metaphysical lessons taught by the translucence, depth and flow of water? Do we give due regard to those elemental forces which formulate us or we also share the same sin with Coleridge's ancient mariner, and that too, without any sense of repentance? How have we managed our precious resources which we found through that ice cracked by the first person narrator in Thoreau's Walden? Despite our high sounding claims of ascent we may see the pit dug by us around. Fatally fallen down on a barren ground of wasteland today our civilisation stinks of commercial and industrial waste. Water that served as the source of life is robbed of its purity and vitality. In our frivolous activities we have polluted the flow of life symbolised in water.

Eliot's well known long poem The Wasteland is a very good example of what appears as a forecast to the modern period. The third part of the poem "The Fire Sermon" begins with the picturesque image of river Thames that must have witnessed the rising and fall of generations on its bank. Human race steps into $20^{\text {th }}$ century. Same water of Walden pond with its chemical composition of $\mathrm{H} 2 \mathrm{O}$ is now seen flowing in the Thames river of England. Thames is a favourite picnic spot during summer. The traces of summer excursion left by the inhabitants of London still echo in the rippling sound of its water. Its rhythm reverberates the soft sound produced by the putrefied litter striking against the flow of the river. Its water bears, "empty bottles, sandwich papers, silk handkerchiefs, cardboard boxes, cigarette ends...other testimonies of summer nights." (Lines: 177-79). During winter, although the river appears deserted and lonesome but the poet can hear the contaminated touch of human presence in "The rattle of the bones," (Line: 186) while "fishing in the dull canal" (Line: 189). The images used by the poet exposes the contamination of Thames' water by Londoners. It forecasts what the river stores for future. The fourth part of the poem titled, 'Death By Water" brings out the imminent perils of degenerating civilisation:

Phlebas the Phoenician, a fortnight dead, Forgot the cry of gulls, and the deep sea swell 
And the profit and loss.

A current under sea

Picked his bones in whispers, As he rose and fell

He passed the stages of his ages and youth

Entering the whirlpool.

(Lines 311-

317)

Throughout the poem The Wasteland water is used as a very prominent symbol. Water which is usually used to symbolize baptism, rebirth, relief, and regeneration seems to connote its reverse in representing degeneration. In The Wasteland, however, projecting the paradox it brings both life and death. It cleanses the Earth but also leaves behind the raw imperfections of humanity. Eliot delineates the ironies associated with human progression through the water symbol. He evinces a premonition along with a warning:

Gentile or Jew

O you who turn the wheel and look to windward

Consider Phlebas, who was once handsome and tall as you. (Lines 318-320)

Underlying a sage advice, the poem warns the man of the outcome of his irrational, inconsiderate and slipshod behaviour. With a horrific picture of present reality, it triggers the issue of what will be the final consequences of subsequent degeneration.

He who was living is now dead

We who were living are now dying

With a little patience (Lines 328-330)

Was it the rational choice man made at the inception of civilisation? What did we crack the ice for; to live without fear of death or to make life more fearsome than death? Are we living a deadly life? We find numerous questions volleyed in our face. Some may be answered but many other float in search of appropriate response. It seems scary but consists of truth. The human civilisation can no more afford to turn its face from the reality of a defaced planet. We all visualise human habitation with certain images worked out in a coherent frame. Having learned since school days we draw a beautiful picture of earth. In our intellectual discourse, we intimately describe our habitat made up of solid 
rock with firm ground surrounded by water. Abundant water in the form of sea, five oceans outlining the seven continents, and so on and on, the imagery expands. It is like reading the globe which we draw in our mind. Our cognitive mapping issues a series of aesthetic metaphors to revel in. With its green trees and running brooks of Forest of Arden we celebrate the nature's promises of a pleasant and carefree life.

And this our life, exempt from public haunt,

Finds tongues in trees, books in the running brooks,

Sermons in stones, and good in everything. (Pg. 70)

But as stated by David Harvey, "There is an omnipresent danger that our mental maps will not match current realities." (pg. 17) bewares us of our misconceptions. In view of man's dilemma of progression, every image comes under questions.

Shakespeare's Forests of Arden starts disappearing into enlarging wastelands. Man no more read the "books in the running brooks" since in the modern wasteland "here is no water but only rock" (Line 331). The globe now is constituted of spreading cities hardened into asphalt roads. It has also hardened the hearts of its inhabitants reflecting the insensitivity of modern urban life. Since the imagery seems wobbling with unpleasant apprehensions, man realises the urgency of introspection. The degeneration of humankind is not merely physical but also moral, ethical and spiritual. Diminishing water flow indicates the dryness of human heart. As Eliot describes:

Here is no water but only rock

Rock and no water and the sandy road

The road winding above among the mountains

Which are mountains of rock without water

If there were water we should stop and drink

Amongst the rock one cannot stop or think

Sweat is dry and feet are in the sand

Dead mountain mouth of curious teeth that can not spit

Here one can neither stand nor lie nor sit

There is not even silence in the mountains

But dry, sterile thunder without rain (Lines 331-341)

Repeating the image of 'no water', 'without water', 'dry sweat', 'no spit', and 'sterile thunder without rain' the poet reverses man's confidence in 
human rationality and his conception of progress. The picture presents a horrific realisation on the part of human civilisation. Since the imagery seems wobbling with unpleasant apprehensions, man realises the urgency of introspection. Now, one is left with only a wish, a wish that subsequently turn into a request. It may only alter into a prayer, a hope that might regenerate the dwindling humankind. Man aspires for dripping drops to instil life in the dying generation. Can we find that regenerating drop borrowed from Thoreau's Walden pond in modern times?

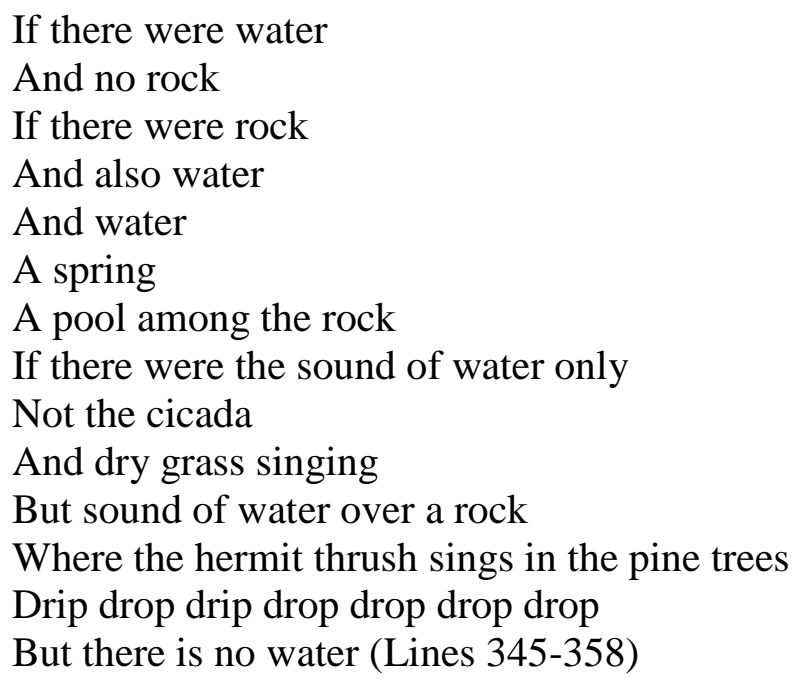

We receive a negative response. The drop seems no more available. And if somewhere the possibility exists, it horrifies with its excessive fearsome force. Since water does not drip down as a regenerating element but when it comes, it comes overflowing to wash away every iota of life. Eliot's imagery of unfertile, famine struck wasteland on the one end and the rippling surface of sea that drowns the sailor on the other end, shows how the human civilisation stands on the verge of destruction. The water considered as a source of life has now turned into the harbinger of death. Whether it is the lack of rainfall or increase of sea level, in both the cases the mankind is cursed to vanish. Either famine or flood; water assuming extreme form pronounces only 'death'. Human being is merely a part of the natural chain. The rational man has forgotten the balance to be maintained for human survival. It is the outcome of man's defiling natural resources like water. Since the human degradation is not confined to one region or one culture, it comes as collective jolt for entire humankind. Inherent in all cultures and civilisations, it yokes together the 
classified East and West. Irrespective of mammoth claims about developing or developed status, the whole $21^{\text {st }}$ century world is destined to bear the brunch of common human folly.

Like American and British literary traditions, Indian literary discourses also use water imagery to muse on the vital social and cultural issues probing into the nature of collective human progress. One of the $21^{\text {st }}$ century Indian writers Arvind Adiga draws a subtle image to bring out the prevailing darkness of contemporary degeneration. In his novel The White Tiger he sketches a black river running through the middle of a modern industrialised city. Without disclosing the identity, he calls it the 'river of death'. It is the river that has been flowing since ancient time but now unrecognisable on account of some self explanatory reasons.

Which black river i am talking of - which river of Death, whose banks are full of rich, dark, sticky mud whose grip traps everything that is planted in it, suffocating and chocking and stunting it? (Pg. 14-15)

Placing the narrative into a cultural context, the picture evoked by the author weaves a thin thread of suspense. Adiga works out the cultural connection through constructing a dialectics of 'I' and 'you' in which two cultures enter into a conversation to comprehend the contemporary reality. The reader's curiosity is aroused and he may seem interested comprehending the whole of the conundrum. The author continues gradually unfolding the identity of this mysterious black river. It is the river that juxtaposes the past and present but ironically being used to expose the terrifying truth of future:

Why, I am talking of Mother Ganga, daughter of the Vedas, river of illumination, protector of us all, breaker of the chain of birth and rebirth. Everywhere this river flows, the area is the Darkness. (Pg. 15)

The river which has reflected the philosophy of a civilisation, which imbibes the cultural richness in its origin, which has been a symbol of purity, piety and progress for ages, gradually degenerates into the river of darkness in $21^{\text {st }}$ century. The river, whose touch was considered healing, is now feared of its noxious contact. Now everyone is cautioned to keep away if not to be plagued by its loathing filth and repulsive human waste: 
No! - Jiabao, I urge you not to dip in the Ganga, unless you want your mouth full of faeces, straw, soggy parts of human bodies, buffalo carrion, and seven different kinds of industrial acids. (Pg. 15)

The holy water which was a symbol of life now makes one experience the disgusting and nauseating degeneration. It witnesses funeral rites and the subsequent decomposition of human body. The exposition does not end here since we are destined to learn even by such sickening realisations. The archetype of birth-death-rebirth reappears in Adiga's description of Ganga ghat. It parallels Eliots projection of the banks of river Thames but in more intense form. Like Eliot's Tiresias, the protagonist of Adiga's The White Tiger also finds himself enlightened through his first hand experience of physical and moral deterioration of human society. His epiphany is the prime source of his knowledge. As a man of intelligence, now he is in position to discern what is wrong with the current reality. He immediately enumerate the lists of "Do's" and "Don't", confessing:

And then I understood: this was the real god of Benaras this black mud of the Ganga into which everything died, and decomposed, and was reborn from, and died into again... Nothing would get liberated here... I haven't been to see the Ganga since then: I'm leaving the river for the American tourists! (Pg. 18)

In addition to his illumination, he alongside exposes the cultural hypocrisy concealed beneath the glorious facade. Whether one acknowledges it or not, the age old flow of water reflects it. How conveniently we may pretend to boast of our cultural richness if it can be en-cashed despite being fully conscious of the hollowness of our big claims. The motifs recurred in Adiga's river is of human greed, selfishness, deception, degeneration and contamination. One may find the group of swindlers on Ganga Ghat thriving on tourism industry and stealing money from the pockets of foreign tourists in the name of sacred river. But water reflects the true face of every object it mirrors. One is compelled to contemplate. The same water, with its chemical combination of Hydrogen and Oxygen, is addressed by different cultural denominations. Whether called as American Walden, or British Thames 
or Indian Ganga, it has always maintained its dignity. It has always served as the basis of human civilisation. Whatever is its cultural identity; it is to be revered, rejoiced and celebrated. How ironical it appears today to see it degenerated in the hands of a progressive $21^{\text {st }}$ century modern man who manipulates its cultural identity for his vested interests. How it is defaced and derided across the strategically laid borders. The translucent water turns black and abhorring.

One can find numerous illustrations of how water is conceived in different shades with subtle metaphorical significations across cultures. The aesthetic construction and reconstruction of water in literary and cultural discourses portrays the realities of human experiences. Water has been a witness of both rational and irrational human behaviour. Its surface always mirrors his true nature. The sound of its flow echoes the melody and melancholy of human progression as the case may be. Matthew Arnold announces in his well known poem, "Dover Beach":

\section{Of human misery; we}

Find also in the sound of a thought, Hearing it by this diastant northern sea (Lines 18-20)

Whether it is a stream or pond or river or sea or ocean, man can see his true face in its translucence. It discloses the incomprehensible truths underlying the human predicament. What could be possibly attributed to it? A true literary artist always tries to decode it. Arnold also attempts to share his detections:

\section{The Sea of Faith}

Was once, too, at the full, and round earth's shore

Lay like the folds of a bright girdle furled.

But now I only hear

Its melancholy, long withdrawing roar,

Retreating...” (Line 21-26)

Water imagery in literature probes into subtle realities of human existence. It raises certain very important issues to bring into debate. Self questioning continues, in fact with more persistence. Are we actually aware of the issues pertaining to our choices? Or we are happy to remain in oblivion to shirk off any responsibility? How far do we acknowledge them? Where does lie the dignity of being human? What do we ascribe to 
for erosion of foundational values? Where does human civilisation stand in the context of present dogma of rationality and irrationality?

Water, water, every where

And all the boards did shrink;

Water, water, every where,

Nor any drop to drink. (Lines 119-122)

How will we explain the irony inherent in the above lines by Coleridge? Are we ready to face the present paradox of 'scarcity in abundance'? No doubt, present hi-tech world is shaped by the unparallel knowledge of human brain. In this age of science man is far superior to the primitive resource less empty handed man who was ruled by nature. With astonishing scientific discoveries and tremendous technological advancement today human being may claim to control these five elemental forces of nature that have given birth to him. They rejoice the power of assuming the role of creator than being called merely a created object. The very fact instantly releases the paradox as a creator always owes certain responsibilities to the power of creation possessed by him.

Man may proudly claim to change the course of stream, but, deterring the free flow of water is like chaining a gigantic force. Perhaps, man has forgotten the simplistic scientific fact that water oozes out from some other channel if forced to be captivated against the astute laws. The nature may appear under the command of hi-tech man but he is ignoring its repercussions. Ice age does not always promise sprouting since past deprived of objectivity does not ensure amelioration in future. Nor our predictions are flawless since every talent has its own limitations. Today, water which solidifies in ice gives impression of a caged tiger. A tiger that has force, strength, pace, vigour and vitality may pose a threat if not properly taken care of. It looks majestic at the same time stirring a scary sensation. Same water which appears pacifying and fulfilling, may lead to doom depending how we treat its natural force.

The ice was here, the ice was there,

The ice was all around:

It cracked and growled, and roared and howled,

Like noises in a swound! (Pg. 35) 
When water is imprisoned it gets stuck. Its melodious murmuring turns into helpless anger growling to resent against human misdemeanour. The melting ice of $21^{\text {st }}$ century warns man of nature's revenge. It is not the question of how much science or how much philosophy, but the rationality of thinking without self deceit. It is the courage of acknowledging and accepting one's mistakes honestly. It is the matter of resolving the ironies of life created by our own.

Indubitably, literature being a perennial form to articulate human thoughts and emotions, presents an interesting account of how human mind perceives the manifested as well as deep lying realities of human experiences. It builds an imagery that not only delineates facts but also reflects profound realisations embedded in them. These realisations connect human soul to universal consciousness. Their combination stirs the thoughts which resonate at a deep level of human perception.

The natural force of the elements like water not only creates life but also sustains it. Its perception throughout imparts it symbolic meaning to comprehend the complexities of human experience. What man need to question today is how much we honour the natural elements which have created the world? Water has power to heal. It nourishes nurtures, revives and restores. Then why does it appear so contaminated and threatening. History may be seen repeating but why does it not suggest any amelioration today? Why do we always seem suspicious of our so called progressive experiments? The world sitting on the volcanic reality of imminent conflagration caused by global warming exposes the irony of scientific progress. Similarly with an apparent social, moral and ethical degradation we feel compulsive of reiterating the eternal values in altered contexts. We may feel contended to rule over the flow of life through deterring the current of water. But being arrested in ice does not picture the optimism of ice age any more. Today ice does not promise to crack for flow but exposes a frigid current recounted in human nerves. Is humanity has stuck in its own false assumptions? Perhaps, Recurring archetypes like the Biblical as well as Vedic image of Great Deluge reveal the irony of progressive degeneration encoded in the literary metaphor of water.

\section{References}

Adiga, Arvind. 2008. The White Tiger. New Delhi: Harper Collins. 
Coleridge, Samuel Taylor. 1993. Selected Poetry. London: Bloomsbury Publishing Ltd.

Connell, Liam \& Nicky Marsh. (Ed.) 2011. Literature and Globalisation: A Reader. New York: Routledge.

Eliot, T. S. 2003. The Waste Land and Other Poems. New York : Peguin Group.

Hodgins, Francis et al. (Ed.) 1989. Adventures in American Literature. Orlando, Florida: Harcourt Brace Jovanovich, Inc.

Jain, Jasbir. (Ed.) 1994. Strings of Gold. New Delhi: Macmillan India Ltd.

Jackson, H. J. (Ed.) 1994. Samuel Taylor Coleridge: Selected Poetry. New York: Oxford University Press.

Shakespeare, William. 1968. As You Like It. New York: Penguin Books. 